Association for Information Systems AIS Electronic Library (AISeL)

MCIS 2009 Proceedings

Mediterranean Conference on Information Systems

(MCIS)

2009

\title{
Human-Centric Ontology-Based Context Modelling In Tourism
}

Carlos Lamsfus

Competence Research Centre in Tourism, carloslamsfus@tourgune.org

David Martin

Competence Research Centre in Tourism, davidmartin@tourgune.org

Zigor Salvador

Competence Research Centre in Tourism, zigorsalvador@tourgune.org

Alex Usandizaga

Competence Research Centre in Tourism, alexusandizaga@tourgune.org

Aurkene Alzua-Sorzabal

Competence Research Centre in Tourism, aurkenealzua@tourgune.org

Follow this and additional works at: http://aisel.aisnet.org/mcis2009

\section{Recommended Citation}

Lamsfus, Carlos; Martin, David; Salvador, Zigor; Usandizaga, Alex; and Alzua-Sorzabal, Aurkene, "Human-Centric Ontology-Based Context Modelling In Tourism" (2009). MCIS 2009 Proceedings. 64.

http://aisel.aisnet.org/mcis2009/64

This material is brought to you by the Mediterranean Conference on Information Systems (MCIS) at AIS Electronic Library (AISeL). It has been accepted for inclusion in MCIS 2009 Proceedings by an authorized administrator of AIS Electronic Library (AISeL). For more information, please contact elibrary@aisnet.org. 


\title{
HUMAN-CENTRIC ONTOLOGY-BASED CONTEXT MODELLING IN TOURISM
}

Lamsfus, Carlos, Competence Research Centre in Tourism, Paseo Mikeletegi, 56 - 201, San

Sebastian, Spain, carloslamsfus@tourgune.org

Alzua-Sorzabal, Aurkene, Competence Research Centre in Tourism, Paseo Mikeletegi, 56 - 201,

San Sebastian, Spain, aurkenealzua@tourgune.org

Martin, David, Competence Research Centre in Tourism, Paseo Mikeletegi, 56 - 201, San

Sebastian, Spain, davidmartin@tourgune.org

Salvador, Zigor, Competence Research Centre in Tourism, Paseo Mikeletegi, 56 - 201, San

Sebastian, Spain, zigorsalvador@tourgune.org

Usandizaga, Alex, Competence Research Centre in Tourism, Paseo Mikeletegi, 56 - 201, San

Sebastian, Spain, alexusandizaga@tourgune.org

\begin{abstract}
A lot of work has been done up to now in the so called context-aware research field on the one hand and on the ontology research field on the other. Research has been conducted both considering context-awareness and ontology as clearly distinct research disciplines and also utilizing ontologies as a tool for context management. However, context-based applications have only been possible at a laboratory environment so far and they have always worked under very certain, pre-established prerequisites in a not very stable nor efficient manner, which actually does not fulfil the nature of Ubiquitous Computing vision. Representation and use of context plays a crucial role in many modern IT applications. The ability to process contextual information and perform context-based reasoning is essential not only for mobile and ubiquitous computing systems, but also for a wide range of tourism applications. This paper presents a novel semantic-based human-centric approach to the notion of context that represents an attempt to make Contextual Computing services available to the general public.
\end{abstract}

Keywords: Context Modelling And Management, Ontology Engineering, Networked Ontologies, Tourism

\section{INTRODUCTION}

Ontologies are now considered (within Computer Science) as a commodity that can be used for the development of large number of applications in different fields such as knowledge management, eCommerce, intelligent integration of information and information retrieval (Corcho et al. 07) amongst others.

Originally, the word Ontology (mind upper case ' $O$ ') (Guarino et al. 95) comes from philosophy. From a philosophical point of view, Ontology is the branch of philosophy that deals with the nature and organization of reality and things. More recently, within Computer Science, ontologies (mind lower case 'o') (Guarino et al. 95) aim at capturing domain knowledge in a generic way and provide a commonly agreed understanding of a domain, which may be re-used across applications (Chandrasekaran et al. 99) (Corcho et al. 01).

Ontologies first started to be used back in 1991 within the context of the DARPA (Defence Advanced Research Projects Agency) Knowledge Sharing Effort (Neches et al. 91) (Corcho et al. 07). The origin of that work was in the efforts the Artificial Intelligence Community was doing at the time to find new ways to share knowledge. In fact, the objective of that project was to explore new ways to construct knowledge-based systems so that knowledge bases upon which the systems were based did not have to be built from scratch, but by assembling re-usable components, saving this way time and money. 
In more recent years, ontologies have extensively been used in Pervasive Computing environments as well as a tool for developing and realising Context Aware systems (Strang 03) (Chen et al. 04b) (Gu et al. 04) (Ay 07). There have even been authors that claim that ontologies are key to the realisation of Context-Awareness (Chen et al. 03). Since Mark Weiser enunciated his vision of a new computing paradigm called Ubiquitous Computing (Weiser 91) a lot of effort has been invested and research conducted into investigating the notion of context and context-aware systems (G. Chen et al. 01) (Vazquez 07). However, these systems have not yet been made available to the general public.

We believe this is due to several reasons, including the lack of adequate infrastructure to develop such applications (Gu 04) (Dey 01), the lack of a common understanding of the notion of context (Ay 07) and the consequent lack of an agreed context model, just to mention a few. Additionally, all of the followed approaches have an eminently techno-centric conception of context, as they all focus on the system rather than on the individual. Moreover, context has never been studied as such, but as a tool for other research fields such as human-computer interaction (Dey 00), software agents (Chen 04) or Distributed Systems (Strang 04) for example, where the authors use contextual information to enhance their systems' functionalities, but not for the sake of studying context itself. In addition, most context-aware applications require populating an area of interest with sensors and additional devices that are utilized to gather contextual information.

The lack of an integrated and operative definition of context as well as a sound context-management model, together with the limiting factor the usage of sensors to gather data represent are some of the reasons why context-awareness is yet limited to certain academic circles and laboratory work, posing serious barriers to the widespread adoption of the context-aware vision.

Context-based applications are the opportunity and the future in the Travel and Tourism Industry (Bernardos et al. 07). According to reports by the WTTC (WTTC) and the UNWTO (WTO) people move more and more frequently (Hall, 2005) and they demand online services anytime, anywhere. The context of a tourist is essential to retrieve relevant pieces of information at a given moment of time as it enables dynamic, personalized delivery of services and information to visitors, significantly enhancing their mobility and tourism experiences. The unexploited potential of Contextual Computing for all kinds of mobility-related scenarios is huge, and tourism and tourists can greatly benefit from a rigorous and inherently enabling approach to context information.

This paper presents a piece of ongoing research work that tackles with the barriers we have encountered that are stopping Contextual Computing applications from becoming universal. It considers the context of a visitor from a totally different point of view to traditional approaches: we place the visitor at the very centre of the problem and we model his context and the domains which are relevant to that visitor with the use of ontologies.

The rest of the paper is divided as follows: Section 2 summarizes the related work found in the literature with regard to context and context-awareness, ontologies and ontologies as tools to model and manage contextual information. We show in Section 3 the motivation underlying this research work as well as some definitions. Section 4 describes the context ontology that we put forward in this paper as well as the development methodology followed to build the ontology. Finally, Section 5 draws some conclusions and remarks some future research lines.

\section{LITERATURE REVIEW}

The history of context aware systems started when Want and colleagues (Want et al. 92) introduced their Active Badge Location System. Baldauf and colleagues (Baldauf et al. 07) refer to this application to be one of the first context-aware applications. This first notion of context in computer science was solely restricted to the location of people in an office environment. However, the location of an individual is only one of a large number of variables that may be used to define context. This definition turns out to be too broad in order to build a contextual-information based system. 
Schilit and Theimer (Schilit et al. 94) are the authors who first used the term context-aware. In their work the authors state that humans live in a mobile and ever changing environment in which they interact with a number of different devices. These authors show a broader notion of context as they assume that context is location as well as other important aspects such as who you are with and what resources are nearby. Still this definition is too wide and somewhat vague. Many concepts ought to be clarified within the definition, e.g. what is that defines who somebody is, or what the coverage of the notion of nearby is in terms of the space scale, etc.

One of the most popular definitions of context has been given by Dey and Abowd (Baldauf et al.07). Their approach to the notion of context is through Human-Computer Interaction abstractions. These authors (Dey et al. 00a) (Dey 01) refer to context as: "any information that can be used to characterize the situation of an entity, i.e. a person, a place, an object, etc., that are considered to be relevant to the interaction between a user and an application, including the user and the application themselves" (Dey, 00. Providing Architectural Support for Building Context Aware Applications, p. 4. Ph.D Dissertation. Georgia Institute of Technology).

One important research question with regard to context is about the way context ought to be managed and used. Unsurprisingly, the lack of a unified and widely accepted answer to this question (as well as a common and sufficiently established understanding on the notion of context itself) has made each researcher focus on the specific context-related functionality they need to apply in their research fields of interest, rather than on context itself.

These first authors working on the realm of context-awareness did not use ontologies to model and manage their idea of context. Ontologies at the beginning of the 90 s were hardly known and by that time their real potential and functionality had still not been recognised. So, ontologies were simply not even considered as an option for context management.

However, in parallel to research conducted in context-awareness, the Artificial Intelligence (Al) community had recognized that capturing knowledge is the key to building large and powerful Al systems and applications (Neches et al. 91). Of course, one of the most complex problems researchers had to face was the need to represent captured knowledge so that they could make some sort of meaningful understanding about it and set the rules under which knowledge could and ought to be shared and re-used across (computing) applications. The problem of Knowledge Representation and Sharing has been widely studied by authors like Allen Newell (Newell 80), Nicola Guarino (Guarino 95), Gruber (Gruber 93) (Gruber 94), Musen (Musen 92) and many others.

Some of the work in $\mathrm{Al}$ at the beginning of the 90s explored the way to use formal ontologies as a way to specify content-specific agreements for sharing and re-using knowledge among software entities (Gruber 94). This way, declarative knowledge, problem-solving techniques and reasoning services could all be shared among systems. In fact, this same conception and philosophy is precisely what underlies within the (ontology or semantic-based) context model that we put forward in this paper: provide the way in which we can share at least part of the (individual's) context with other kinds of context (domains of reality) and thus provide effective context based information services in tourism in an effective anytime, anywhere manner.

Around 2000 research scientists on the realm of context-awareness still did not have a clear idea about the notion of context and still did not have either an agreed context definition or model. Moreover, no research work had properly analysed the generic use of context information in Computer Science. However, the work that had been done on ontologies during the 90s elucidated that they could support knowledge re-use, integration and sharing across applications and therefore several authors converged upon a fact: context information and context models could be handled using semantic technologies (Gu 04) (Chen 04) (Strang 03), as a first step towards standardization or an attempt to making these systems universal.

In particular, they have used ontologies to represent their context models and manage contextual information in an efficient and organized manner. Regarding the nature of context, these authors simply 
take Dey's definition and apply semantic technologies to build information systems on top of it. These authors claim that ontologies may provide a shared context model. In addition to that, ontologies can be further used for reasoning (infer high level implicit context from low level explicit context, for example) as well as to detect data consistency and duplicity.

The Literature Review reveals that most research in the field of context and contextual computing is not focused on context itself, but on particular uses of context: authors consider it as a simple set of variables which are relevant to their application field of interest and tend to contextualize the environment of the individual, not the individual within the environment. These approaches turn out to be extremely restrictive and miss the potential contributions in the field of contextual computing.

This is also one of the reasons why there is not an agreed definition of context, because the objective of the piece of research has not been context, it has been something else. In fact, due to their emphasis in contextualizing the environment, most of the existing research work revolves around the existence of a network of sensors in the environment and other specifically deployed devices and SW solutions, missing what we believe to be the greatest and most meaningful contextual information source: the Internet. The use of sensors poses in our opinion one of the greatest barriers that is preventing Contextual Computing applications from becoming universal. Still in tourism, location based and context-based applications have to get off the ground (Buhalis et al. 08).

\section{MOTIVATION AND DEFINITIONS}

\subsection{Motivation}

According to figures provided by the United Nations World Tourism Organization (UNWTO) and the World Travel and Tourism Council (WTC) the Travel and Tourism industry is one of the largest and most important industries in the entire world.

Around $90 \%$ of the visitors around the World carry a mobile electronic device with them at all times and require in some way or another to be connected to sources of information, such as the Internet. This kind of devices, e.g. mobile telephones, PDAs and the like are fast evolving into miniature computers. In fact, devices such as Apple's iPhone, Google's Android, the new Nokia E series, etc. have impressive computing capabilities and are fast blurring the vague line between laptop computers and mobile devices. These new generation mobile devices are regarded as the main access to the Internet in the future. In addition, connectivity technologies, such as 3G, UMTS, HSDPA, Wi-Fi, etc. allow visitors to be connected almost anytime and anywhere to information sources.

Given the enormous amount of information that exists in the Internet, to access the right piece of information at a particular moment could be a real challenge to say the least. In this sense, the role of the visitor's context is crucial as it can be used as a kind of filter to access a particular piece of information that is relevant to support and enhance the visitor's mobility.

\subsection{Definitions}

\section{Contextual Computing}

Firstly, we would like to make a remark on how we refer to the discipline under discussion within the paper.

Most of the literature refers to context-aware systems or applications to denominate systems that make use of information that originates within the context in which they run. These applications have been programmed to automatically react (in various ways) to changes that occur in their environment without explicit human intervention. However, we consider that this way of functioning does not make 
these systems either aware of their context or intelligent as we argue that awareness is an eminently human ability and as such, computers cannot be aware of anything. These (context-aware) systems have been enabled to detect, gather, manage and process contextual information under certain rules or system governing regulations. They just process information. This is the reason why we would rather talk about Contextual Computing, rather than talking about context-awareness. As our domain of application is the Travel and Tourism industry, then we refer to Contextual Computing in tourism.

So, for us, Contextual Computing is the scientific discipline that studies and observes the context of an individual and pursues to generate knowledge out of the observation in terms of how to model an individual's context and how to manage information originated in that context. It also explores how that information can be processed in a way that it is useful for the individual.

\section{Definition of Context}

The concept of "visitor" is defined by the UNWTO as "a traveller taking a trip to a main destination outside his/her usual environment, for less than one year for any main purpose (business, leisure, or other personal purpose) other than to be employed by a resident entity in the country or place visited. These trips are taken by visitors qualify as tourism trips. Tourism refers to the activity of all visitors", (UNWTO International Recommendation for Tourism Statistics, 2008, p. 10).

We propose to study the context of the visitor as such context, i.e. not as an auxiliary variable of something else. We focus on the domain of the application and attempt to generate knowledge out of the questions originated from that observation. Under these circumstances: what is that defines the context of an individual? What is the minimum amount of information that we need to define that individual's context? Where is it (the information) and how can we obtain contextual information? How can we translate that context into a computing model so that it can provide the visitor with relevant information to enhance his mobility?

In addition, we propose to gather contextual information from alternative sources of information regardless of the existence of sensor networks. We propose to use the Internet as the main contextual information source that can be complemented with mobile device incorporated sensors (e.g. GPS). This way we would avoid having to populate a particular area of interest with sensors. The objective is not to contextualize a particular area, but to contextualize a particular individual at a particular location at a particular moment of time by the use of web-based information. This way, we expect to set the conceptual foundations for meaningful contributions in the fields of contextual computing and tourism. We believe this is one first step that could contribute to universalize Contextual Computing systems and making them available to the general public.

Our model of context focuses on the human being itself, it does not consider an application, a service or the context information that may be relevant for the application to run more efficiently. It considers the information that is relevant to characterize the situation of a tourist and that can be beneficially used to enhance, improve and assist visitors while en route. In this sense we would like to propose a definition of the notion of context of our own which is based upon the definition put forward by Dey (Dey 00): "Context is any relevant information that characterizes the situation of a visitor. A visitor is a traveller taking a trip outside his/her usual environment and her situation is specified by data concerning a) the individual itself, b) the individual's environment (and surroundings) and c) the individual's objective at a particular moment of time. This information can be of use for a computing-application in order to support the visitor's mobility".

\section{Justification of the context ontology}

Strang and colleagues (Strang et al. 03) studied various kinds of context models. They analyzed them according to requirements they had set themselves for Ubiquitous Computing systems and they found as a result that ontologies clearly fulfil all requirements and are one of the most adequate (if not the most) tool to model contextual information. In fact, one of the biggest advantages of ontologies is their 
flexibility and capability to model a domain and, hence, conceptualize the portion of reality to which such a domain refers (Toro et al. 08).

Strictly from a pure theoretical point of view, based upon the original philosophical conception of the notion of Ontology, according to Aristotle (Klimovski 05) the way in which science is communicated is based on language, i.e. semantics. So, Semantics in Aristotelian philosophy represent the relationship there is between the reality of things in the world (Aristotle's concept of Ontology) and the idea (model) that we form of them in our minds.

A context model is a formal representation of the individual's context. The model can be constructed through a set of concepts, properties and relations, i.e. ontologies. In addition to that, a context model is an abstraction of an individual's context in reality at a given moment of time. Therefore, as well as we use semantics (i.e. natural language) to explicitly express our idea about the world, ontology semantics (i.e. ontology development languages) can convey the reality of the model to a computing entity.

This parallelism between the notion of Ontology in Philosophy and the notion of ontology within Computer Science as a tool to model context theoretically and conceptually grounds the use of ontologies to model context. The abstraction of reality (i.e. context of an individual at a given moment of time, Ontology) in a computing system can be represented through ontologies. The relationship that exists between the model (mental abstraction) and the reality is expressed through semantics (language) (Klimovski 05) as well as the computing model of context (ontology) can be expressed through the (ontology's) semantics, i.e. ontology languages.

Besides, ontologies have proved to be good intermediation tools in information integration. This is crucial in our vision of context: under this vision firstly, we contextualize the visitor and secondly, we divide the world in different domains, e.g. a city, museum, restaurant, etc. As both the visitor's context and the domains will be modelled by the use of ontologies it will be very simple to attach the different ontologies and have them work together, allowing interoperability and interaction among context models. In addition, ontologies can also provide reasoning functionalities that are valid for the context model.

Finally, it would be very convenient to be able to detect or reason on the activity the visitor is undertaking at the particular moment of time. This is one of the reasons why we shall use ontologies to model visitors' context.

\section{System Architecture}

Building contextual computing systems involves several challenges, such as gathering, modelling, storing, and managing contextual information. These challenges justify the need for an architectural support to provide an efficient infrastructure for building this kind of systems.

The architecture is based on a layered distribution in order to separate low-level tasks (discovering and gathering context, storing) from high level tasks (managing context, querying). It consists of the following interconnected components distributed on different layers. 


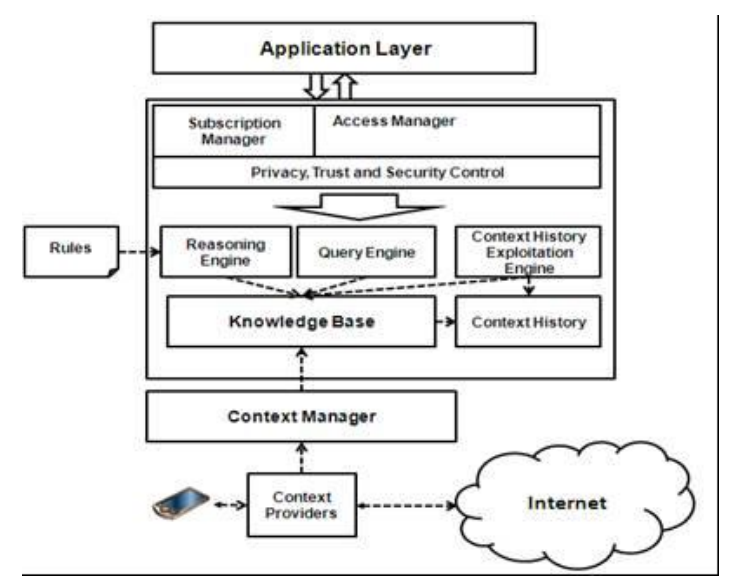

Figure 1: Proposed system architecture

- Context providers. They are used to acquire context data from heterogeneous sources. They can acquire context information from web sources, e.g. weather web services, or from the visitor's mobile device, e.g. profile, location. This is one of the novelties within our system: we are not limiting the use of our system to a particular predetermined sensor-populated location, but we can use it in every single place where there is telephone network coverage that enables access to information sources;

- Context manager. It gets the information from all the context providers and it is responsible for gathering context, transforming context data into the ontological model and merging all data into de Knowledge Base. It offers a centralized way to access context data sources;

- Knowledge base. It stores all the statements about tourist's context by the use of ontologies;

- Context history. A historical database of past context variables' values is stored here. This can be useful to predict future visitor situations by the use of the Context History Exploitation Engine or to reason over current values of context variables, e.g. the coordinates given by the mobile device GPS incorporated sensors correspond to Athens and they do not exist in the Context History database, therefore, the visitor is in Athens for the first time;

- Reasoning engine. It is used to obtain high level context (situations) based on defined rules or the semantics of information that has been gathered and stored in the Knowledge Base;

- Query engine. It allows queries about context information, as location, temperature or higher level context;

- Privacy, Trust and Security Control: Given that contextual information may have very sensible personal information, we need to consider a module within the architecture that actually takes this fact into consideration and that allows the visitor decide to what extent she wants to share personal information either with others or with the system;

- Access manager. It manages the interaction between the platform and the application layer. This interaction can be in a request/response manner or in subscription basis, where the platform sends context information according to defined events (context changes, time intervals); 
- Application layer. Application that can interact with the platform in order to adapt its behaviour to the user's context.

\section{DEFINITION OF THE CONTEXT ONTOLOGY AND ITS CONSTITUENTS: CONTOLOGY}

We shall determine which the constituents of context are based upon the definition of the notion of context we have put forward earlier in this paper, the architecture that we have presented in the previous section and on the final objective of the Contextual Computing Application that we are designing. These constituents of context will end up being one ontology each within the ContOlogy network of ontologies and will define the relationships among them.

However, we need to distinguish several issues at this point. We take Davenport's (Davenport et al. 01) definition of data and information, whereby: "Data are the values of parameters (definition) and variables that result from some kind of work" and "Information is communicated data, i.e. there is a transmission channel as follows: there are agents in form of sender and receiver, there is a channel that is being used to communicate and, finally there is an encoding and decoding process".

Within the definition of context, three different categories of data can be found:

- Category a: refers to information about the visitors themselves;

- Category b: refers to information about the individual's environment;

- Category c: refers to the intentions and objectives of the individual, i.e. data about the next future that compared to the information that describes the context of the visitor at a given moment of time could define what the relevant information the visitor needs at that particular moment of time.

This information is hardly transferable to a computing model that represents the context of a visitor at a given moment of time. We need to define variables that represent data belonging to each category. These variables will then be used in the computing model and this model will behave according to the values of these variables.

In order to define the variables, we shall use the 5W (Dey and Abowd 00) (Who, What, When, Where and Why) and one $\mathrm{H}$ (How?) as basic information gathering system within the context of the visitor:

- Information about category a), i.e. information about visitors themselves, i.e. information about the visitor as a human being and some characteristics inherent to the visitor as such. This information can be obtained by answering the who, what and how questions:

- Who is the visitor? The "who" can be defined by the visitor's id, her mood, her profile and her role;

- What is that visitor doing? Task, activity;

$\circ$ How is the visitor proceeding? Device;

- Information about category b), i.e. information about the visitor's environment, i.e. the set of relevant elements or entities that happen to be at the same location as the visitor. Explicit entities, such as infrastructure -network-, can also be taken into account within this category. This information can be obtained by answering the where, when and how questions:

- Where is the visitor? Location (coordinates, reasoning street, city, country potentially obtainable), weather conditions (temperature, sunny, etc.);

- When is the visitor at that location? Time, date, etc.

- How? Device (type of device), network and connectivity information;

- Information about the visitor's objective can be obtained by answering the why question: 
$\circ$ Why is the visitor at that location? (Intention);

What is going to do next?

- What are his needs?

We aim to re-use as much existing contextual models that are supported by a significant numbers of practitioners as possible. Therefore, we will not develop a single ontology but a network of ontologies, i.e. a collection of ontologies that are related among them by properties (Haase et al.06).

Despite the fact that there are already a considerable number of context modelling ontologies, they are still in an early preliminary experimental phase. As it is the case with most of the work that has been done up to now, they have been defined for different specific uses and cover different domains. Therefore they have been basically designed for specific purposes which make them hardly re-usable. Hence, no consensual model exists that can broadly be re-used for modelling context in applications. Furthermore, even if there have been plenty of efforts for developing context ontologies, only few of them are available to be studied in detail and reused; these are the CoDAMoS (Preuveneers, et al. 2004), GUMO (Heckmann et al. 2005) and SOUPA/COBRA-ONT ontologies (Chen et al. 05), CC/PP (W3Ca 2004) and Delivery Context Ontology (W3Cb 2008).

\subsection{Ontology Building Methodology}

Different methodologies to build ontologies have been reported in the literature (Gruber 94) (Grüninger et al. 95) (Uschold et al. 96) (Bernaras et al. 96) (Noy et al. 01) (Corcho et al. 01) (Gómez-Pérez et al. 03). However, due to the fact that we are planning to build a network of ontologies rather than a single ontology from scratch, we shall use the NeOn methodology for developing ontology networks (SuárezFigueroa et al. 2008).

Both the literature and experience have shown that the ontology building process is iterative. Therefore, the ContOlogy context ontology network will be implemented in three consecutive iterations, each of them providing a working prototype of the ontology network suitable for validation of the model. This approach is different from others in terms that it does not have a double ontology conception of context, i.e. a core ontology and other domain ontologies. Rather, it focuses on the different constituents of context (derived from the definition of the notion of context, architecture of the system and main objective of the system) and develops an ontology for each of the constituents. This adds modularity and flexibility to the ontology model that we are proposing in this paper. Domain ontologies that represent specific parts of the world could be aligned to ContOlogy according to the particular context of a visitor at a given moment of time.

At the moment of writing this paper, we have completed the first iteration of the ontology network development. In this iteration our goal was to obtain a first set of ontology requirements and a first prototype of the ontology network that could be used in early stages of the project. The results of the evaluation of this first iteration of the context networked ontology (ContOlogy) will be used, together with other information sources (e.g., empirical data) in future iterations. As it has been argued in the literature, the insufficient involvement of final users (visitors in this case) in the construction of ontologies is a significant cause for the current shortage of and the unsatisfying coverage found in domain ontologies (van Damme et al. 2007)

The following represent some of the activities we have carried out up to now within the first iteration of the ontology development process: ontology specification, scheduling, re-use of ontological resources and ontology implementation. The following table presents the result of this work

\begin{tabular}{|c|c|}
\hline Ontology & Definition \\
\hline Visitor (WTO, 2008) & $\begin{array}{c}\text { Characteristics of the } \\
\text { human being in mobility }\end{array}$ \\
\hline Profile & Information that describes \\
\hline
\end{tabular}




\begin{tabular}{|c|c|}
\hline & the visitor's preferences \\
\hline Motivation (WTO, 2008) & $\begin{array}{l}\text { Classification based on } \\
\text { main purpose of mobility }\end{array}$ \\
\hline \multicolumn{2}{|l|}{ Activity } \\
\hline \multicolumn{2}{|l|}{ Task } \\
\hline Device & $\begin{array}{l}\text { Physical object the visitor } \\
\text { carries with him }\end{array}$ \\
\hline Network & $\begin{array}{c}\text { Infrastructure to connect } \\
\text { devices and convey } \\
\text { information }\end{array}$ \\
\hline Intention & An aim, plan or purpose \\
\hline Location & $\begin{array}{l}\text { Coordinates that define } \\
\text { where a visitor is at a } \\
\text { given moment of time }\end{array}$ \\
\hline Time & $\begin{array}{l}\text { Physical dimension that } \\
\text { measures spam between } \\
\text { facts }\end{array}$ \\
\hline Weather & $\begin{array}{l}\text { Meteorology conditions at } \\
\text { the given location }\end{array}$ \\
\hline
\end{tabular}

Table 1: Result of first iteration of ContOlogy.

Some of the ontologies (Activity and task for example) have not yet been implemented at this stage of the ontology building process. They shall be tackled in the following iteration. Moreover, the ontologies within the network are related to each other via typical properties, such as is_a, has, etc.

\subsection{Use case validation}

The tourism domain is widely considered to be one of the emerging industrial sectors where mobile services are highly demanded. In fact, in 2015 there will be more than 3 billion travellers around the world and they will demand more ubiquitous services, specific to the situation of each individual, as well as to their personal preferences under specific circumstances. Surveys reveal that over $90 \%$ of travellers carry a mobile device with them. Thus, tourism turns out to be a very adequate application domain for contextual computing services.

The following use case scenario has been designed in order to validate the proposed context definition and context model as well as the proposed architecture to support contextual computing tourism services. Such services can be driven to support the traveller's mobility while the visitor be at a particular unusual destination.

Let us consider a particular individual that has arrived in a city with his wife. That information can be obtained by the location of the mobile devices of both individuals: both of them are located together in this new city to visit. Also, based on the context history it is known that the travellers are visiting the city for the first time. The mobile phones send their location coordinates as well as their owner's identity to the Context Provider. The Context Manager inserts this information on the Knowledge Base and the system concludes through reasoning that the couple is in that city for the first time.

The system then explores on their profile. Given that the individuals are not familiar with the city, the different possible places to visit are selected by the service based on the user's combined preferences (topics that the users were interested in previous similar situations, i.e., while visiting new cities in the past). Finally, a first place to visit is displayed on the mobile phone screen.

The system has determined through reasoning that the travellers arrived in the city by train, therefore the previous information is shown in the screen along with the public transport options available. While on the bus, the travellers do not know in which bus stop they need to get off the bus. Given their current location, the location of the point interest of their choice and the closest bus stop to the point of 
interest, the system warns them about the most convenient bus stop. The service will keep the travellers informed about such topics, specific to route events while visiting the city.

The individuals may also get information about nearby museums compatible with the user's preferences or hobbies. Specifically, the users may get special last-minute offers, based on the fact that they can be very close to the museum. For instance, a museum that might be interesting for the users is displayed on the mobile phone. In ten minutes time, a visit group is available with two free places to complete the group. Given that the museum is interested in completing the visit group, the users subscribed to the contextual recommendation service get special last-minute discounts if they are close to the museum. They could also get indications on how to reach the museum.

\section{CONCLUSIONS AND IMPLICATIONS}

We discuss in this paper a different approach to the notion of context and context-awareness to that proposed so far in the literature that is called Contextual Computing. In particular, we focus on Contextual Computing Services in tourism, although the most general aspects of our contribution are relevant to all of the so called context-aware scientific research discipline.

We have thoroughly analyzed most of the relevant existing literature and we have concluded that (i) neither does consensus exist on a definition for the notion of context nor do existing ones suite the tourism domain, (ii) a sufficiently agreed model of context and method for contextual information management does not exist, (iii) the existing works reveal the need of a scientific approach to the study of context on its own and (iv) the use of sensors to gather contextual information poses a serious barrier as pre-requisite for making Contextual Computing systems universal.

The specific contributions of this piece of (ongoing) research work tackle with these problems and propose different alternatives.

Firstly, we have proposed a new definition of context aiming at integrating and making the notion of context more operative. This new definition of context is human-centred and contextualizes the individual at a given location. It observes the nature of human mobility and opens new chances to study complex scenarios.

Secondly, this approach does not require the use of sensors to capture contextual information in addition to the ones that are already present in the mobile device. We argue that the individual may be contextualized according to certain existing parameters and Web based information sources, instead of contextualizing a system or a particular environment. As a consequence, the amount of imposed preconditions with regard to existing research approaches is greatly reduced.

This approach makes the application independent from the need to have a sensor populated area in a location of interest. In addition, it also avoids the great amount of complex work that had to be carried out under the existing approaches to make context-aware applications run. This is one first step to make Contextual Computing applications available to everyday users on the one hand and to universalize them on the other hand.

Thirdly, by using a network of ontologies to model context, we are providing a framework of interoperability for other kinds of systems, as ontologies have shown to be an appropriate tool for data exchange and integration. Besides, ontologies provide reasoning capabilities which are particularly interesting for data inference, consistency checking and detection of data duplicity.

In contrast to the frequently used double ontology approach to model context (one core context ontology and several domain specific ontologies) the network of ontologies that we propose allows to easily align domain specific ontologies to the network as one more constituent of the context of a visitor at a given moment of time. 
The model we put forward however presents a number of limitations. As we are proposing not to use conventional sensors, the applications' contextual information has to rely on Web based information, i.e. we need to rely on the fact that data is accurate and that it is being continuously updated. Furthermore, there are some kinds of data that cannot be obtained anyways, e.g. noise level, lightning level, etc. and therefore context information is not as rich as it could by the use of these kinds of sensors. We argue that this information however is not strictly relevant for a tourism application and furthermore, the fact of not having sensors makes it easier to make Contextual Computing applications universal.

Still there are a lot of open questions. Firstly, further research is needed on connectivity technologies. The existing ones provide mobile internet access to a reasonable cost provided we are not under a roaming service, which considerably raises the connection price. Wi-Fi, RFID, Bluetooth and other connectivity technologies could help on the way. More research is necessary as well on middleware technologies and platforms to find out to what extent they can support Contextual Computing applications efficiency in a domain-divided world. It is essential to understand how the Future Internet is going to impact on Context models, even more considering that the presented new paradigm does not consider to use conventional sensors to gather contextual information.

Real visitors shall be involved in an experimental phase of the ontology development. This will allow to find out more about intentions and motivations of a visitor en route in order to include these into the network of ontologies. This is something that has not yet been considered in other context ontologies and as it has previously been stated, the participation of real users may improve the usefulness of the final ontology.

\section{Acknowledgements}

The authors would like to thank the Basque Government for having partially funded the imFUTOURnet project within the Etortek strategic research programme and the research undertaken for the purpose of this paper.

\section{References}

Ay, F., 2007. Context Modelling and Reasoning using ontologies.

Baldauf, M., 2007. A Survey on Context-aware systems. International Journal Ad-Hoc and Ubiquitous Computing, 2, pp. $263-277$.

Bernaras, A., Laresgoiti, I., Correa, J., 1996. Building and reusing ontologies for Electrical Networks applications. In Proceedings of the $12^{\text {th }}$ European Conference on Artificial Intelligence.

Bernardos, A. B., 2007. Servicios y aplicaciones en movilidad para el sector turístico. CITIC 2007.

Buhalis, D., Pistidda, L., 2008. The impact of WiMAX on Tourist Destinations. In Proceedings of the ENTER 2008 Conference. Innsbruck, Austria, pp. 383 - 394.

Chandrasekaran, B., Josephson, J. R. and Benjamins, R., 1999. What are ontologies and why do we need them? In IEEE Intelligent Systems, pp. $22-26$.

Chen, G., Kotz, D., 2000. A survey of context-aware mobile computing research. Tech-Report TR2000 381. Darmouth College.

Chen, H. L., 2004. An Intelligent Broker Architecture for Pervasive Context-Aware Systems. Department of Computer Science and Electrical Engineering, University of Baltimore, PhD Thesis.

Chen, H., Finin, T., Joshi, A., 2003. An ontology for Context-Aware Pervasive Computing Environments.

Chen, H., Finin, T., Joshi, A., 2004. A Context Broker for Building Smart Meeting Rooms.

Chen, H., Perich, F. Finin, T., Joshi, A., 2004. SOUPA: Standard Ontology for Ubiquitous and Pervasive Applications.

Chen, H., Finin, T. and Josh, A. 2005. The SOUPA Ontology for Pervasive Computing. In Ontologies for Agents: Theory and Experiences, pp. 233-258. 
Corcho O., Fernández-López, M., Gómez-Pérez, A., 2007. Ontological Engineering: what are ontologies and how can we build them? Chapter III, p. 44-70.

Corcho, O., Fernández-López, M., Gómez-Pérez, A., 2001. OntoWeb: Technical Roadmap. Universidad Politécnica de Madrid.

Damme, C. v., Hepp, M., Siorpaes, K., 2007. FolksOntology: An Integrated Approach for Turning Folsonomies into Ontologies. In Proceedings of the ESWC Workshop "Bridging the Gap between Semantic Web and Web 2.0".

Davenport, T. H., Prusak, L., 1998. Working Knowledge: how organizations manage what they know. Ed. Harvard Business School Press.

Dey, A. K., 2000. Providing Architectural Support for Building Context-Aware Applications. Georgia Institute of Technology, Ph.D. Thesis.

Dey, A. K., 2001. The Context Toolkit. A Toolkit for Context Aware applications.

Dey, A.K., Abowd, G.D., 2000. Towards a better understanding of context and context awareness. Proceedings of the workshop on the What, Who, Where, When and how of Context Awareness, ACM Press, New York. 2000.

Gómez-Pérez, A., Fernández-López, M., Corcho, O., 2003 Ontological Engineering. ISBN 1-85233-551-3. Springer Verlag.

Gruber, T. R., 1993. A transaction approach to portable ontology specifications. Knowledge Acquisition, Vol. 5, pp. $199-220$.

Gruber, T. R., 1994. Toward Principles for the Design of Ontologies Used for Knowledge Sharing. In Formal Ontology in Conceptual Analysis and Knowledge Representation. Kluwer Academic Publishers. 1994

Gu, T., Pung, H. K., Zhang, D. Q., 2004b. A service oriented middleware for building context-aware services. Journal of Network and Computer Applications, pp. $1-18$.

Gu, T., Wang, X. H., Hung K. P., Zhang, D. Q., 2004: An Ontology-based Context Model in Intelligent Environments. In Proceedings of the Communication Networks and Distributed Systems Modelling and Simulation Conference.

Guarino, N., 1995. Formal ontology, conceptual analysis and knowledge representation. International Journal of Human and Computer Studies, p. 625-640.

Grüninger, M., Fox, M., 1995. Methodology for the Design and Evaluation of ontologies.

Haase, P., Rudolph, S., Wang, Y., Brockmans, S., Palma, R., Euzenat, J. and d'Aquin, M., 2006. NeOn Deliverable D1.1.1 Networked Ontology Model.

Hall, M., 2005. Tourism: rethinking the social science of Mobility. Ed. Pearson Education Limited.

Heckmann, D., Schwartz, T., Brandherm, B., Schmitz, M. and von Wilamowitz-Moellendorff, M., 2005. Gumo - The General User Model Ontology. In User Modeling, 428-432

Klimovski, A., 2005. Las desventuras del conocimiento científico. Ed. A Z. ISBN 950-534-275-6.

Musen, M. A., 1992. Dimensions of Knowledge Sharing and Reuse. Computers and Biomedical research, pp. $435-467$.

Neches, R.; Fikes, R.; Finin, T.; Gruber, T.; Patil, R.; Senator, T. \& Swartout, W., 1991. Enabling Technology for Knowledge Sharing. Al Magazine

Neches, R.; Fikes, R.; Finin, T.; Gruber, T.; Patil, R.; Senator, T. \& Swartout, W., 1991: Enabling Technology for Knowledge Sharing. Al Magazine.

Newell, A., 1980. The Knowledge Level. Al Magazine.

Noy, N., F., McGuinness, D. L., 2001. Ontology Deveopment 101: A guide to creating your first ontology. Stanford University.

Preuveneers, D., Van den Bergh, J., Wagelaar, D., Georges, A., Rigole, P., Clerckx, T., Berbers, Y., Connix, K., Jonckers, V. and de Bosschere, K., 2004. Towards an Extensible Context Ontology for Ambient Intelligence.

Schilit, B. N.; Adams, N. W. R., Roy, W., 1994. Context-Aware Computing Applications.

Strang, T., 2003. Service-Interoperabilität in Ubiquitous Computing Umgebungen. Ph.D. Thesis, TUMünchen. 
Strang, T., Linnhoff-Popien, C., 2004. A Context-Modelling survey. First International Workshop on Advanced Context Modelling, Reasoning and Management. UbiComp.

Suárez-Figueroa, M. C., Aguado de Cea, G., Buil, C., Dellschaft, K., Fernández-López, M., García, A., Gómez-Pérez, A., Herrero, G., Montiel-Ponsoda, E., Sabou, M., Villazón-Terrazas, B. and Yufei, Z., 2008. NeOn D5.4.1: NeOn Methodology for Building Contextualized Ontology Networks. NeOn project.

Toro, C. A., Sanín, C., Szczerbicki, E., Posada, J., 2008. Reflexive Ontologies: Enhancing Ontologies with Self-Contained Queries. Cybernetics and Systems, 39:2, pp. 171- 189.

United Nations World Tourism Organization, UNWTO. http://www.wto.org

Uschold, M., Grüninger, M.,1996. Ontologies: Principles, Methods and Applications. Knowledge Engineering Review, vol. 11, pp. $93-155$.

Vázquez, I., 2007. A behavioural model for Context-Aware Semantic Devices. Ph.D Dissertation. Universidad de Deusto.

Want, R., Hpper, A., Falcao, V., Gibbons, J., 1992. The Active Badge Location System. ACM Transactions on Information Systems, pp. $91-102$

Weiser, M., 1999. The Computer of the 21st Century. SIGMOBILE, Mobile Computing and Communications Review, 3(3):3-11.

World Travel and Tourism Council. http://www.wttc.org

World Travel and Tourism Council, 2008. International Recommendations for Tourism Statistics. ST/ESA/STAT/SER.M/83/Rev.1

W3C, World Wide Web Consortium, 2004. Composite/Capability/Preference Profiles (CC/PP): Structures and Vocabularies 1.0. W3C Recommendation 15 January 2004 http://www.w3.org/TR/CCPP-structvocab/

W3C, World Wide Web Consortium, 2008. Delievery Context ontology. W3C Working Draft 15 April 2008. http://www.w3.org/TR/dcontology/ 